\title{
Formation of Social and Pedagogical Values in Future Teachers for Working with Migrant Children in the Process of Professional Training
}

\author{
Anastasiya Smirnaya \\ Reshetnev Siberian State University of Science and \\ Technology \\ State Institute of Arts \\ Siberian Federal University \\ Krasnoyarsk, Russia \\ E-mail: nastenasm@yandex.ru
}

\author{
Julia Shepeleva \\ Reshetnev Siberian State University of Science and \\ Technology \\ State Institute of Arts \\ Siberian Federal University \\ Krasnoyarsk, Russia \\ E-mail: Lady-bomg@yandex.ru
}

\begin{abstract}
The article shows the socio-pedagogical context of professional training of the future teacher. The concepts of "social and pedagogical values" and training of the future teacher for working with migrant children are defined. The basic components of social and pedagogical values are "the person has an intrinsic value in the fullness of his potential and actual existence" and "multiculturalism as an integrative quality of personality". Formation of a conscious attitude of the socio-pedagogical values of the future teacher for work with migrant children occurs through the inclusion of students in the construction of an information-cognitive model and the creation of role experimentation situations. Finally, the future teacher masters the ways of working with migrant children through practical activities such as training, exercises, problem solving, movies, debates, discussions, and others.
\end{abstract}

Keywords-social and pedagogical values; future teachers; migrant children

\section{INTRODUCTION}

Currently, there is a need for interdisciplinary synthesis of knowledge of the person as a pedagogical strategy. Transformation in all spheres of life in Russian society requires the higher education system educate bachelors and masters students who will be able to provide assistance and support to vulnerable population segments. Competent executing of social and pedagogical functions plays an important role in the professional activity of teachers where their main characteristics are valuable knowledge, valuable relations, and valuable actions. Based on the fact that the Russian Federation today is a multi-ethnic state, a modern teacher consequently educates children from different ethnic groups. This is connected with increased migration movements in recent decades. Since the education system is a key institution of socio-cultural adaptation, a significant factor in the professional training of the future teacher as a multicultural personality becomes a valuable aspect, implying formation of his conscious attitude to the sociopedagogical values as a carrier and translator of professionally and personally significant qualities.
Solution of this issue is connected with the resolution of a number of contradictions between the requirements of society of the future bachelor which are intended to be led by axiological guidelines for professional activity and insufficiently expressed professional training aimed at familiarizing them with these guidelines; the need for modern pedagogical practices in the executing of sociopedagogical functions of the future teacher while working with migrant children, and poor development of social and pedagogical provisions.

Changes in the nature of education connected with multiculturalism and tolerance are increasingly reflected in the main functional components of the competencies of future teachers. These include the demonstration of pedagogical ethics, emotional responsiveness, professional creativity, generalized strong-willed qualities, research activity, and verbal accessibility in communication. These require a fundamentally new approach to the training of the future teacher. Generally, competencies are developed through the creation of pedagogical conditions which involves a combination of different forms, methods, techniques, and means of training.

\section{SOCIO-PEDAGOGICAL CONTEXT OF PROFESSIONAL TRAINING OF THE FUTURE TEACHER}

Training as a general term is used in relation with the applied tasks of education, when it means development of social experience for its subsequent application, realizing specific tasks of a practical, cognitive, or educational plan related to a particular activity.

The concept is used in two ways: as "learning" - the formation of readiness to perform tasks; and as the actual readiness - the presence of competence, knowledge, and skills required to perform tasks. The structure of readiness also includes setup of the person to the relevant actions [1]. This article considers "training" in the context of the first meaning. 
The main purpose of higher education is the training of a bachelor or master with a professional, creative personality. As an individual, this is a citizen who can think globally and humanistically, and act locally and creatively. At the same time, particularly important is the formation of professional and personal values of the trainee, which determine the quality parameters of his/her further professional activity.

The main scientific approaches to the professional training of teachers are considered in the works of V.A. Adolf, O.S. Grebenyuk, T.E. Demidova, I.A. Zimnyaya, A.K. Markova, V.A. Slastenin, A.P. Tryapitsina, N.V. Chekaleva, and other scientists. In scientific research, only the basis for the study of the contents of the activities of the future teacher with migrant children is laid. The contents and organization of pedagogical process in professional readiness are reviewed in the research by O.V. Amosova, A.P. Bespalko, G.K. Selevko, T.I. Shamova, M.I. Shilova, N.E. Schurkova, et al.

From the analysis of these studies, professional work is considered as an activity in a particular microenvironment according to the interests of harmonization of life and social relations of individuals or groups of people [2]. Universally, pedagogical strategies also provide a significant social impact on the activities of the future teacher. In this regard, the socio-pedagogical context of the teacher is one of the important components of his profession.

The socio-pedagogical context of the future teacher training is quite clearly reflected in basic professional principles: professional competence in determining problems of social formation of the individual and ways to promote the development of social competence; humanism and empathic involvement with others; goodwill while interacting with the individual in need of assistance or in a critical situation; timeliness of pedagogical support to the student; complexity and integration of the social and pedagogical system; and the design of versatile support in the personal solution of vital tasks [3].

Training the future teacher to work with migrant children is complex. It is associated with the need to simultaneously perform several professional functions at different levels: micro - individual, child, meso-group, and family members; and macro - society and state. Questions devoted to training future teachers to work in multicultural schools are found in many works by A. K. Lukina. Features of the University stage of training for a bachelor's degree while preparing for interaction with migrant children are associated with the specifics of professional activity. They are humanistic, as well as with practice-oriented training, goal-setting and content selection, organizational, and methodological components of the system [4].

Professional readiness in the works of V.A. Slastenin is defined as "a special mental state, as the presence of the subject's image of the structure of a certain action and the constant orientation of consciousness to its implementation" [5]. Readiness, according to A.V. Smirnova, is the result of training and is manifested in the awareness of professional tasks, including mastering the system of knowledge, skills, and motivation [6]. The pedagogical process is carried out in specially organized conditions which are associated with the contents and methods of pedagogical interaction. Training of the future teacher for interaction with migrant children and their families involves the development and implementation of certain contents and methods of training, allowing them to reach the necessary level of preparation of the teacher to solve the problems of interaction with migrant children. Improving the process of training future teachers to work with migrant children allows considering this training as a system, process, and result of targeted educational activities based on the principles of multiculturalism and dialogue between cultures. This is aimed at the formation of sociopedagogical values, and the development of knowledge, skills, and methods of activities that characterize the effectiveness of coordination of actions of subjects and their cooperation.

From this perspective, the practical socio-pedagogical context of the teacher's activity of any level of readiness is a necessary component of successful professional activity. From the authors' point of view, the main tasks of social and pedagogical activity, and the means of their solution, are the following: The first task is to produce social competence of the teacher, carried out through his social training. The second task is to develop a set of qualities (social adaptability, social autonomy, social activity, tolerance, etc.) necessary for the teacher to interact with migrant children and their families, which are implemented on the basis of social education. The third task is to assist in overcoming difficulties of socio-cultural adaptation arising in the process of interpersonal relations between children, implemented through socio-pedagogical support. Each task is differentiated in relation to different categories of population which researchers combine into different groups.

Hence, the socio-pedagogical activity of the teacher while working with migrant children, reflecting one of the specific features of the professional sphere, "person-toperson", is aimed at helping the student and his family, in order to mobilize internal resources; and to stimulate and organize active actions to solve life problems.

\section{FORMS OF JOINING SOCIAL AND PEDAGOGICAL VALUES OF FUTURE TEACHERS}

One of the forms of joining future teachers to sociopedagogical values is the construction of an informationcognitive model [7]. Such construction takes place in the laboratory, i.e., practical lessons using essays, discussions, special tasks, diagnostic techniques, and heuristic methods.

The development of the model is aimed at introducing students to a humanitarian orientation of the concepts of "values", "professional values", and "social and pedagogical values". Identification and analysis of basic social and pedagogical values implies the person "as an intrinsic value in the fullness of its potential and actual existence" and multiculturalism as "an integrative quality of personality".

The first stage of students' inclusion in modeling is to understand the essence of social and pedagogical values. At this stage, which is substantially associated with the "idea of socio-pedagogical values", students are divided into two 
subgroups. They are invited to write an essay on the topics: "Person as an intrinsic value in the fullness of its potential and actual existence" and "Multiculturalism as an integrative quality of personality". Heuristic methods of teaching are used at all stages of the work. At this stage of modeling, heuristic methods such as the construction of concepts and "word formulas" are used. Students associate the method of constructing concepts with the actualization of their existing ideas about social and pedagogical values. In comparing and discussing these ideas of values, the teacher helps students to "finish" them to cultural forms. At the same time, students are offered the following tasks: building a "Model of a morally responsible student", "Qualities characterizing moral responsibility", "Cooperation; an exercise in responsible assignment". A case study is examined: "Business negotiations", situations of role experimentation "Premium Fund", "Telephone conversations", and "Planned vacation" [8].

After writing an essay and working with "verbal formulas" future teachers are combined into groups. Each subgroup holds a general discussion of its work, the desired result of which is: clarification of concepts, development of a common concept, and definition of key points of the discussion. During the discussion, students express their point of view on how they see the person as a value in itself that includes culture as a pedagogical value. In the accompanying activity, the idea occurs of the need to develop the willingness of students to work together (as a team) in accordance with the principles of business communication and cooperation, to organize and coordinate the work of small groups, and to interact in concert with the various participants of professional activities.

In the second stage of the modeling process "understanding" of the professional importance of social and pedagogical values - each student is given individual tasks:

Task 1. Describe qualities in the thesaurus group according to four axiological orientations (spiritual, creative, organizational, and praxiological).

Task 2. Create a portrait of a teacher interacting with migrant children. It should be endowed with certain sociopedagogical values, which are reflected in his professional qualities.

These tasks are performed by students in the framework of individual work on the subject of "Pedagogics". At this stage of work, such heuristic methods as a mass "brain attack" are used, which significantly increases the efficiency of generating new ideas when assessing qualities; the method of self-organization of training - work with textbooks and primary sources when the proposed tasks are done; and the method of free association, in which the extraordinary relationships between the components of the problem being solved and the elements of professional activity are established.

In the third stage of the modeling process, the construction of an information-cognitive model is necessary to create a model that will reflect the basic values and their value orientations. The creative team, together with the teacher, designs the model. This work is carried out with the use of heuristic methods of group work organization (method of reviews, method of projects, and direct collective "brainstorming").

As the result of this work, an information-cognitive model is constructed that reflects basic socio-pedagogical values and specific axiological orientations (spiritual, creative, organizational, and praxiological) of the future teacher.

Within the model there are two groups of basic values: the Human Being as self-value in the fullness of his potential and actual existence, and Multiculturalism as an integrative quality of personality. The spiritual indicator reflects orientation of the teacher working with migrant children to the highest human values. The essence of this indicator is expressed in humanity and other qualities that contribute to the development of "pedagogical wisdom" as the highest manifestation of pedagogical skill. The creative indicator reflects teacher's orientation on the values of pedagogical creativity, which indicates his readiness to transform and create pedagogical reality and self-improvement in the process of implementing the socio-pedagogical function of the school. The organizational indicator is associated with multiculturalism as a socio-pedagogical value, which shows mastering of organizational values by the future teacher. The praxiological indicator shows abilities, skills, social and pedagogical activity skills, that, in turn, indicate the joining of the social and pedagogical values.

The results of constructing a model of socio-pedagogical values were made by students in the form of a computer presentation. The presentation includes several slides, where students define the model name, the purpose and stages of the model design process, and display the model itself in the form of a diagram. The model is called "Information and cognitive model of familiarizing the student to social and pedagogical values". The purpose of the model development process: formation of students' ideas about social and pedagogical values. Modeling stages: Stage 1 -"clarifying" of the essence of social and pedagogical values; Stage $2-$ "comprehension" of the professional importance of social and pedagogical values; and Stage 3 - "construction" of the model. At the end of the lesson, an analysis of the model is made and the participants independently evaluate results of the work.

Another form of joining the future teacher with the sociopedagogical values is the creation of role experimentation aimed at an awareness of socio-pedagogical values as professionally significant. Based on the features of the sociopedagogical function of the teacher, situations of role experimentation are divided into two groups. The first group is situations in which the issue of interaction with migrant children is of primary importance; this is focused on the subject. The situation is created according to the desired result: to help adapt the child in the class, and to form a tolerant attitude of students to each other. Therefore, these situations are called "object-oriented"; that is, aimed at the development of pedagogical methods, techniques, and means of helping children to solve the problem. The second group 
of situations, "subject-oriented", is focused on understanding the problems of the student, on providing him with pedagogical support, updating his personal potential, while taking into account his psychological characteristics, behavior, and social environment.

Included in "object-oriented" situations are related situations such as rituals of social failure and activating substantive work. The essence of these situations is that the student or his family cannot solve the problem by updating personal opportunities. "Subject-oriented" situations are represented by situations involving creativity and spiritual states of interpersonal experience which suggest that the student or his family has sufficient personal potential for successful solution of the problem. Each of these types includes several variants of situations with its conventional name. The list of these options is unlimited and is determined by creative abilities of future teachers to design situations of role experimentation in different contents. The typology of situations of role experimentation of the future teacher when working with migrant children is presented in the form of a block diagram in "Fig. 1".

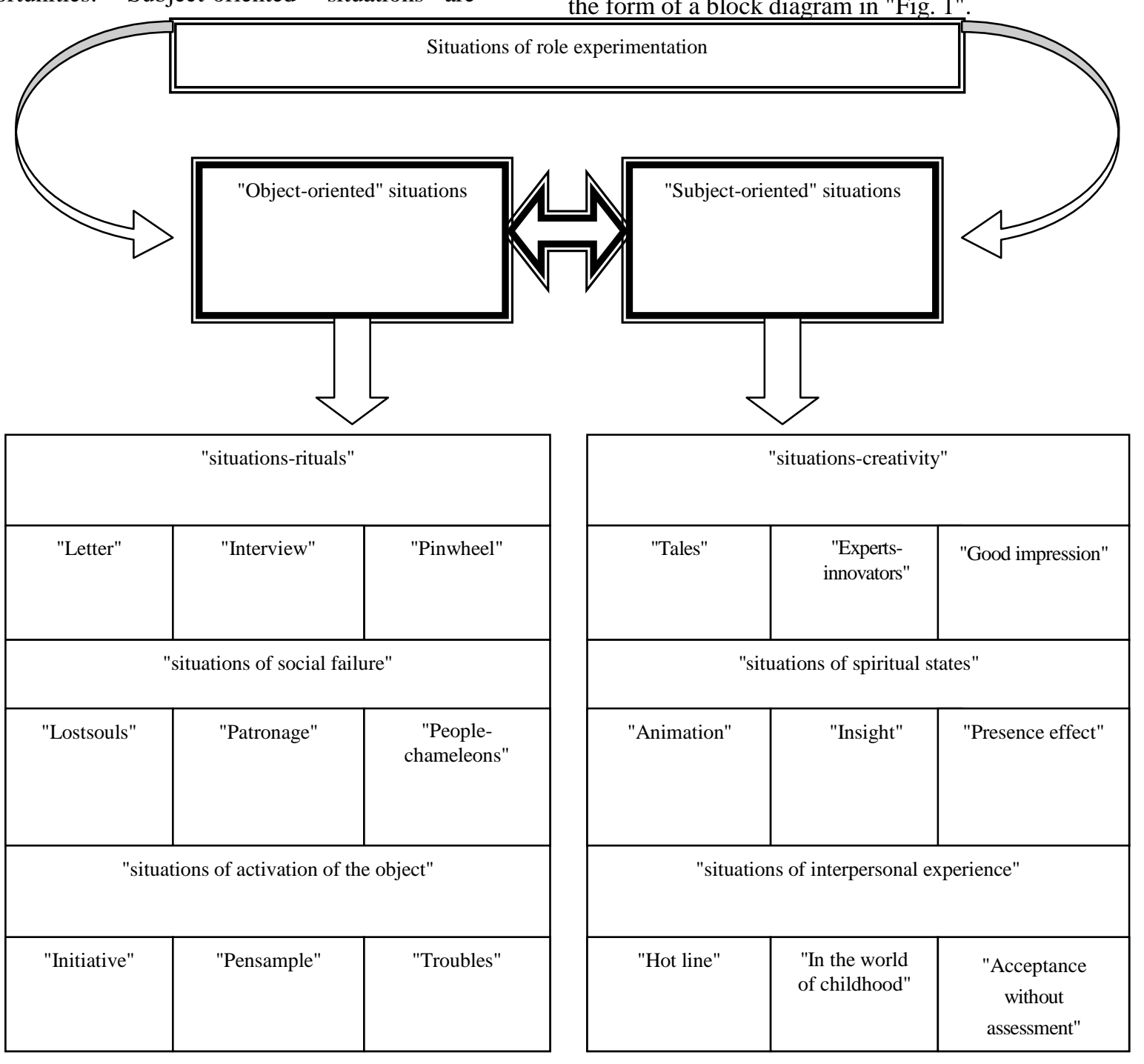

Fig. 1. The typology of situations of role experimenting.

\section{CONCLUSION}

Within the limitation of the scope of the article, characteristics are defined of the situations of role experimentation. The situation "initiative" is based on the exchange of information in the collective discussion about the manifestation in teacher's behavior such qualities as initiative and attitude to initiative people. Students give examples and facts from teacher's activities, when timely and appropriate manifestation of this quality leads to the disclosure of the personal potential of the child or his family, the teacher's self-realization in social and pedagogical activities, success in work, and achieving a high degree of professional competence.

Thus, the assistance to the future teacher in creating situations of role-playing experimentation consists of pedagogical actions that stimulate the activities of students in the design of situations of role-playing experimentation and their critical analysis. This activates the search for an adequate solution to these situations and attitudes about 
social and pedagogical values. Role-playing these situations includes understanding their contents, evaluation, and forecasting of socio-pedagogical results.

The study of the formation of socio-pedagogical values of future teachers for work with migrant children in the process of professional training concludes:

- "Socio-pedagogical values" are a combination of spiritual, creative, organizational, and practical guidelines. They reflect the basic socio-pedagogical values of: the Person as self-valued in the fullness of its potential and actual existence; and Multiculturalism as an integration of personality and determining the effectiveness of the solution of professional problems;

- The stages of formation of students' conscious attitude to social and pedagogical values in the process of professional training at the University are: the inclusion of students in the development of information-cognitive model; and creating situations of role-playing experimentation with the assistance of a teacher.

\section{REFERENCES}

[1] Encyclopedia of professional education: In 3 volumes / ed. by S.Y. Batyshev. - Moscow: APO, 1998. Vol. 2, 602 p. - p. 272

[2] A. A. Smirnaya, The introduction of a future specialist of social work to the social and pedagogical values: dissertation of candidate of pedagogical Sciences: 13.00.08 / Smirnaya Anastasiya Andreevna. Krasnoyarsk, 2008, 279 p. - p. 40.

[3] Working book of social pedagogue: manual for self-education / ed. by N.F. Maslova. Eagle, 1995, Part II, 160 p. - p. 20.

[4] Formation of identity and tolerance of the individual in terms of multicultural education: monograph / A. K. Lukina [and others.]; resp. ed. A. K. Lukina, Krasnoyarsk: Sib. Fed. Univ., 2015, 260 p.

[5] V. A. Slastenin, Pedagogics / V.A. Slastenin, I.F. Isaev, E.N. Shiyanov / V. A. Slastenin (ed), Moscow: Academy, 2002, 576 p. - p. 87.

[6] A. V. Smirnova, The preparation of future teachers at the University to interact with the family: dis. ... cand. ped. sciences. Krasnoyarsk, 2013, 249 p. - p. 72.

[7] A. A. Smirnaya, Development of information and cognitive model of social and pedagogical values in the context of development of professional competences of students // The Role of science in society: collected articles of the International scientific-practical conference. Research center "Aeterna"; Executive editor A.A. Sukiasyan, 2014, pp. 169-172.

[8] S. A. Saprygina, The formation of the moral responsibility for the future of the bachelor in vocational and cultural areas: abstract dis. ... the candidate of pedagogical Sciences: 13.00.08. - Krasnoyarsk. State Pedagogical University named after V. P. Astafyev. Krasnoyarsk, 2016, 24 p. 